reached. Suggested guidelines are as follows: chyle leak of greater than $1 \mathrm{~L}$ per day for more than 5 days or persistent leak for more than 2 weeks of treatment. These guidelines have been drawn on the basis of the comparison of conservative treatment with thoracotomy and not on the setting of thoracic trauma. The advent of video-assisted thoracoscopic surgery over the last decade has changed the approach to the management of a number of chest diseases. Because of the lower morbidity associated with videoassisted thoracoscopic surgery (less pain and pulmonary dysfunction), the guidelines regarding the timing of surgical intervention must be reviewed. ${ }^{5}$ In the case reported here, we adopted an early surgical intervention approach because of vascular compromise of the left upper arm despite pleural drainage.

The thoracic duct was reached through the right pleural cavity, although the chylothorax was in the left. The advantages of this access route are fewer anatomic variations of the duct at the point where it enters the thorax and a cleaner operating area free of previous dissections, fibrin clots, or an incarcerated lung.

\section{References}

1. Dulchavsky SA, Ledgerwood AM, Lucas CE. Management of chylothorax after blunt chest trauma. $J$ Trauma. 1988;28:1400-1.

2. Cox CS Jr, Allen GS, Fischer RP, Conklin LD, Duke JH, Cocanour CS, et al. Blunt versus penetrating subclavian artery injury: presentation, injury pattern, and outcome. J Trauma. 1999;46:445-9.

3. Aerts NR, Poli de Figueiredo LF, Burihan E. Emergency room retrograde transbrachial arteriography for the management of axillosubclavian vascular injuries. J Trauma. 2003;55:69-73.

4. Danetz JS, Cassano AD, Stoner MC, Ivatury RR, Levy MM. Feasibility of endovascular repair in penetrating axillosubclavian injuries: a retrospective review. J Vasc Surg. 2005;41:246-54.

5. Kumar S, Kumar A, Pawar DK. Thoracoscopic management of thoracic duct injury: is there a place for conservatism? J Postgrad Med. 2004; 50:57-9.

\title{
Two-staged treatment of bronchial carcinoid without pulmonary parenchymal resection
}

\author{
Motoyasu Sagawa, MD, Makoto Sugita, MD, Sumiko Maeda, MD, and Tsutomu Sakuma, MD, Uchinada, Ishikawa, Japan
}

T ypical carcinoid of the bronchus is regarded as a low-grade malignancy. ${ }^{1,2}$ Although surgical resection is the most appropriate form of therapy, the extent of resection should be limited, favoring preservation of pulmonary function. Preferred procedures include sleeve lobectomy and sleeve segmentectomy. ${ }^{1-3}$ We herein report a case of bronchial carcinoid located in the right intermediate bronchus. Treatment consisted of endobronchial resection of the tumor and resection of the intermediate bronchus with complete preservation of the pulmonary parenchyma.

\section{Clinical Summary}

A 38-year-old woman was transferred to our hospital for the treatment of a polypoid tumor causing almost complete obstruction

From the Department of Thoracic Surgery, Kanazawa Medical University, Uchinada, Ishikawa, Japan.

Received for publication Oct 22, 2005; accepted for publication Nov 7, 2005.

Address for reprints: Motoyasu Sagawa, MD, Department of Thoracic Surgery, Kanazawa Medical University, 1-1 Daigaku, Uchinada, Ishikawa 920-0293, Japan (E-mail: sagawam@ @anazawa-med.ac.jp).

J Thorac Cardiovasc Surg 2006;131:753-4

$0022-5223 / \$ 32.00$

Copyright $\odot 2006$ by The American Association for Thoracic Surgery doi:10.1016/j.jtcvs.2005.11.008 of the right intermediate bronchus (Figure 1, A). Because the accurate peripheral extent of the tumor was unable to be evaluated, our initial treatment strategy involved endobronchial resection of the tumor. Under local anesthesia, endoscopic resection using electrosurgery was performed with a flexible bronchoscope and a snare. Pathologic examination of the resected tumor provided the diagnosis of typical carcinoid.

After endobronchial resection, the extent of the tumor's base was observed bronchoscopically. Located in the medial wall of the right intermediate bronchus, the base of the tumor extended axially, and almost the entire length of the intermediate bronchus was involved (Figure 1, B). Chest computed tomography revealed no lymph node swelling. On the basis of these findings, we conducted the second stage of treatment, namely a wide resection of the right intermediate bronchus without resection of the pulmonary parenchyma.

With the patient under general anesthesia with a doublelumen endotracheal tube, a thoracotomy was performed. The pulmonary ligament was freed for mobilization of the right middle and lower lobes, and the right main and intermediate bronchi were dissected out from the surrounding tissues. The external surface of the bronchus was found to be smooth, indicating that the tumor had not penetrated the full thickness of the bronchial wall, which was later pathologically confirmed. Wide resection of the whole length of the medial wall of the right intermediate bronchus was carefully performed. The lateral wall of the intermediate bronchus was preserved (Figure 2, $A)$. Pathologic examination revealed that the tumor was completely resected. Sixteen sutures of Maxon 3-0 (Sherwood, 

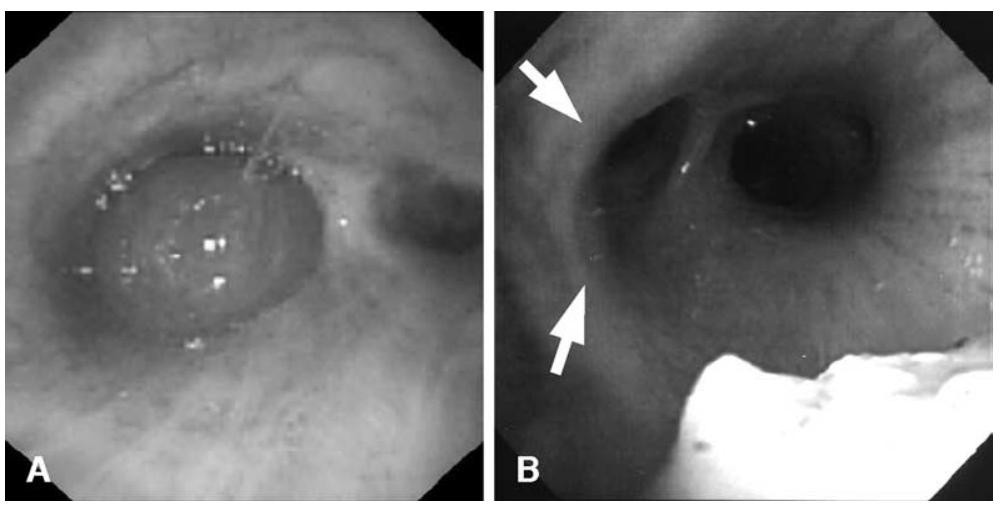

Figure 1. A, Polypoid tumor almost completely obstructing the right intermediate bronchus. B, After the endobronchial polypectomy. The distal margin of the tumor is located near the orifice of the right middle lobe bronchus (white arrows).
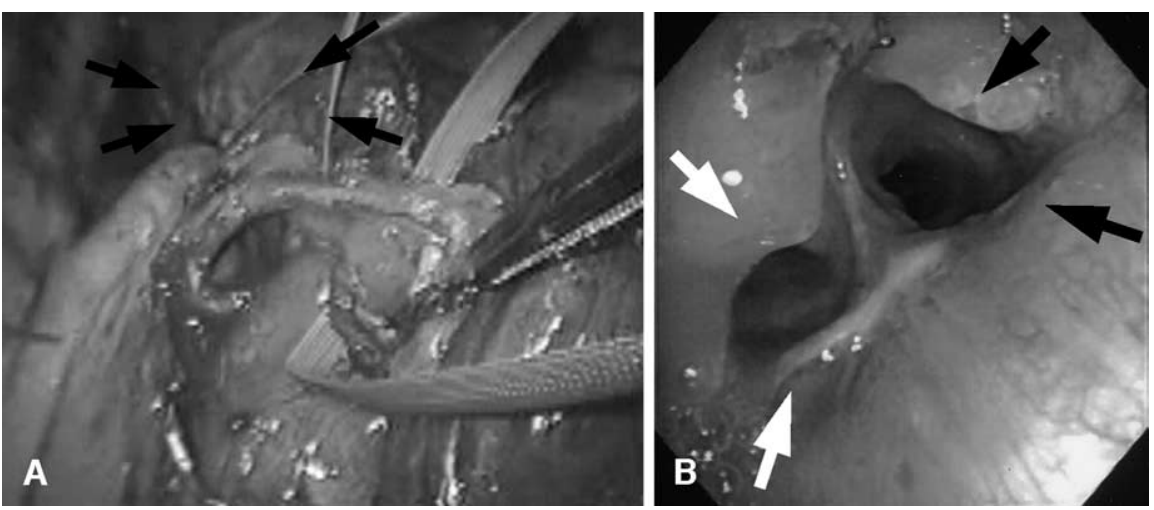

Figure 2. A, After wide resection of the medial wall of the right intermediate bronchus, the proximal stump of the residual bronchus is near the right upper lobe bronchus (black arrows) and the distal stump is just over the orifice of the right middle lobe bronchus. B, Postoperative bronchoscopic examination revealing slight deformity of the anastomosis and no stenosis (white arrows, right middle lobe bronchus; black arrows, right lower lobe bronchus).

Davis \& Geck, St. Louis, Mo) were placed for anastomosis of the bronchus. The resected subcarinal and hilar lymph nodes were examined and found to be free of carcinoid metastasis.

The patient's postoperative course was uneventful. Two months after surgery, bronchoscopy revealed only slight deformity of the anastomosis with no stenosis (Figure 2, B). Her chest roentgenogram was clear. On admission, her vital capacity (VC) and forced expiratory volume in 1 second $\left(\mathrm{FEV}_{1}\right)$ were $3040 \mathrm{~mL}$ and $2430 \mathrm{~mL}$, respectively. Two months after surgery, her VC was $2960 \mathrm{~mL}$ and her FEV 1 was $2680 \mathrm{~mL}$. One year after surgery, the patient was found to be healthy, with no respiratory symptoms or signs of recurrence.

\section{Discussion}

Sleeve lobectomy and sleeve segmentectomy are sometimes conducted for patients with bronchial carcinoid to preserve pulmonary function. ${ }^{1-3}$ There have been a few reports concerning bronchial resection and endto-end anastomosis without pulmonary parenchymal resection. ${ }^{3-5}$ In the present case, the accurate extent of the tumor was unable to be evaluated because the tumor almost completely obstructed the right intermediate bronchus. If we had conducted thoracotomy first, it would have been difficult to select an appropriate surgical procedure intraoperatively. Therefore, we adopted two-staged treatment for the patient. After endobronchial polypectomy was performed as the first stage of treatment, the lateral wall of the intermediate bronchus was found to be intact. This further influenced the decision to perform wide resection of the medial wall of the intermediate bronchus as the second stage of treatment. As an additional advantage, suturing for this procedure was very easy because part of the bronchial wall remained fixed.

At the end of the patient's first postoperative year, a thorough evaluation showed she was healthy, with no recurrence of the carcinoid. The condition of the bronchial anastomosis was good, and the patient's pulmonary function was well preserved.

We consider this two-staged procedure to be safe, easy, and useful to preserve postoperative pulmonary function. We recommend it for the surgical management of tumors of low-grade malignancy, such as bronchial carcinoid.

\section{References}

1. Filosso PL, Rena O, Donati G, Casadio C, Ruffini E, Papalia E, et al. Bronchial carcinoid tumors: surgical management and long-term outcome. J Thorac Cardiovasc Surg. 2002;123:303-9.

2. Ducrocq X, Thomas P, Massard G, Barsotti P, Giudicelli R, Fuentes P, et al. Operative risk and prognostic factors of typical bronchial carcinoid tumors. Ann Thorac Surg. 1998;65:1410-4.

3. Bueno R, Wain JC, Wright CD, Moncure AC, Grillo HC, Mathisen DJ Bronchoplasty in the management of low-grade airway neoplasms and benign bronchial stenosis. Ann Thorac Surg. 1996;62:824-9.

4. Newton JR Jr, Grillo HC, Mathisen DJ. Main bronchial sleeve resection with pulmonary conservation. Ann Thorac Surg. 1991;52:1272-80.

5. Cerfolio RJ, Deschamps C, Allen MS, Trastek VF, Pairolero PC. Mainstem bronchial sleeve resection with pulmonary preservation. Ann Thorac Surg. 1996;61:1458-63. 